\title{
Absolute Reticulocyte Count and Reticulocyte Hemoglobin Content as Predictors of Early Response to Exclusive Oral Iron in Children with Iron Deficiency Anemia
}

\author{
Emilia Parodi, ${ }^{1}$ Maria Teresa Giraudo, ${ }^{2}$ Fulvio Ricceri, ${ }^{3}$ Maria Luigia Aurucci, ${ }^{4}$ \\ Raffaela Mazzone, ${ }^{5}$ and Ugo Ramenghi ${ }^{4}$ \\ ${ }^{1}$ Pediatric and Neonatology Unit, Ordine Mauriziano Hospital, Largo Turati 62, 10128 Turin, Italy \\ ${ }^{2}$ Department of Mathematics "G. Peano", University of Turin, Via Carlo Alberto 10, 10123 Turin, Italy \\ ${ }^{3}$ Unit of Epidemiology, Regional Health Service ASL TO3, Via Sabaudia 164, Grugliasco, 10095 Turin, Italy \\ ${ }^{4}$ Hematology Unit, Department of Sciences of Public Health and Pediatrics, University of Turin, Piazza Polonia 94, 10126 Turin, Italy \\ ${ }^{5}$ Hematology and Coagulation Laboratory, Città della Scienza e della Salute Hospital, Piazza Polonia 94, 10126 Turin, Italy
}

Correspondence should be addressed to Emilia Parodi; emilia.parodi@unito.it

Received 30 December 2015; Revised 2 March 2016; Accepted 3 March 2016

Academic Editor: Maria Stella Figueiredo

Copyright (C) 2016 Emilia Parodi et al. This is an open access article distributed under the Creative Commons Attribution License, which permits unrestricted use, distribution, and reproduction in any medium, provided the original work is properly cited.

\begin{abstract}
We report data regarding kinetic of response to oral iron in 34 iron deficiency anemia children. Twenty-four/34 patients (70.5\%) reached reference value of hemoglobin $(\mathrm{Hb})$ concentration for age and sex at day +30 from the beginning of treatment (complete early responders (CERs)), and 4/34 (12\%) reached an $\mathrm{Hb}$ concentration at least 50\% higher than the original (partial early responders (PERs)). CHr at T1 (within 7 days from the beginning of treatment) was significantly different in the different groups (22.95 in CERs versus 18.41 in other patients; $p=0.001 ; 22.42$ in early responders versus 18.07 in NERs; $p=0.001$ ). Relative increase of CHr from T0 to T1 resulted significantly higher in CERs than in other patients $(0.21$ versus $0.11, p=0.042)$ and in early responders than in NERs $(0.22$ versus $0.004, p=0.006)$. Multivariate logistic models revealed a higher probability of being a complete early responder due to relative increase of ARC from T0 to T1 $[\mathrm{OR}(95 \% \mathrm{CI})=44.95(1.54-1311.98)]$ and to CHr at T1 [OR $(95 \% \mathrm{CI})=3.18(1.24-8.17)]$. Our preliminary data confirm $\mathrm{CHr}$ as early and accurate predictor of hematological response to oral iron.
\end{abstract}

\section{Introduction}

Reticulocytes are the youngest erythrocytes released from the bone marrow into circulating blood. Under normal conditions, after maturing for 1-3 days within the bone marrow, they are released into peripheral blood where they circulate for 1-2 days before becoming mature erythrocytes. The reticulocyte hemoglobin content $(\mathrm{CHr})$ provides an indirect measure of the functional iron available for new red blood cell production over the previous 3-4 days [1]. $\mathrm{CHr}$ in peripheral blood samples has been proven to be a useful marker for diagnosis of iron deficiency and iron deficiency anemia (IDA) both in children [2-4] and adults [5].

Brugnara et al. [6] demonstrated that $\mathrm{CHr}$ also provides an early measure of the response to parenteral iron therapy increasing within 2-4 days of the initiation of intravenous iron therapy.

The goal of therapy for IDA, the most common hematological disease of infancy and childhood, is to supply sufficient iron to repair the hemoglobin $(\mathrm{Hb})$ deficit and replenish storage iron [7]. Oral iron administration is a wellestablished effective and worldwide accepted treatment for anemia derived from inadequate dietary iron intake because of its efficacy, safety, and cost-effectiveness [8]. Thus, in our Pediatric Hematology Unit, oral iron treatment is the first-line therapy for all children with IDA with anamnestic suspicion of inadequate iron intake, independently of base $\mathrm{Hb}$ level. Recently, we have identified absolute reticulocyte count (ARC) and $\mathrm{CHr}$ as accurate and precocious markers in order to early detect early responders to exclusive oral iron 
therapy in a small cohort of pediatric patients with severe iron deficiency anemia (IDA) [9]. These preliminary results in children with very low base $\mathrm{Hb}$ levels (median $\mathrm{Hb}$ level before treatment $6.3 \mathrm{~g} / \mathrm{dL}$; range $4.5-7.0$ ) prompted us to investigate the efficacy of reticulocyte parameters in monitoring the response to oral iron supplementation in a larger cohort of pediatric patients.

\section{Materials and Methods}

2.1. Patients and Hematological Evaluation. Clinical records of patients referred to our Pediatric Hematology Unit for IDA between July 1, 2012, and June 30, 2014, were retrospectively analyzed.

Patients who matched inclusion criteria and did not present exclusion criteria were included in the study. Data about patients with an age between 6 months and 16 years, a hemoglobin level more than 2 standard deviations below the mean reference value for age and gender, a transferrin saturation $<15 \%$, and a high anamnestic suspicion of inadequate iron intake were analyzed. Patients with diagnosis of celiac disease, positivity of fecal occult blood test, or positivity of Helicobacter pylori fecal antigen test were excluded. Patients from our preliminary report were not included in the present study [9].

All children with these characteristics had started a firstline treatment with exclusive oral iron supplementation at a dosage equivalent to $2 \mathrm{mg} / \mathrm{kg} / \mathrm{die}$ of elemental iron. In all patients but one, who underwent therapy with liposomial iron, bisglycinate chelate iron was administered.

Data about $\mathrm{Hb}$ levels and reticulocyte parameters (ARC and $\mathrm{CHr}$ ) at diagnosis, before treatment (T0), within 7 days (T1), and at day +30 (T2) from the beginning of iron supplementation, were extrapolated from clinical records of each patient and analyzed with analytical methods.

$\mathrm{Hb}$ and reticulocyte parameters on peripheral blood samples had been measured with an automated flow cytometer (Advia 120 Bayer $^{\circledR}$ ) with optic measure; reticulocytes had been stained with dye oxazine 750. Approximately 50.000 cells had been counted for each red blood cell and reticulocyte determinations.

2.2. Statistical Analysis. We described data as number and frequencies or mean and standard deviation for qualitative and quantitative variables, respectively.

Differences between different groups of patients were tested using Fisher's exact test or Wilcoxon sum rank test (due to the not normal distribution of all the values as established by means of Shapiro-Wilks normality tests), as appropriate.

To account for possible confounding variables, we performed a multivariate logistic model, adjusting for age, sex, and $\mathrm{Hb}$ value at diagnosis.

Relative increase of $\mathrm{ARC}$ and $\mathrm{CHr}$ from $\mathrm{T} 0$ to $\mathrm{T} 1$ was computed as (T1 value - T0 value)/T0 value.

All tests were two-sided and a $p$ value lower than 0.050 was considered significant. Analyses were performed using SAS V9.4.
2.3. Definitions. Response was defined as early and complete if patients reached mean $\mathrm{Hb}$ reference value for age at day +30 (T2) from the onset of iron therapy (complete early responders (CERs)).

Response at T2 was defined as early and partial if patients reached an $\mathrm{Hb}$ concentration at least $50 \%$ higher than the original one, computed as ( $\mathrm{Hb} \mathrm{T} 2-\mathrm{Hb}$ T0)/Hb T0 (partial early responders, PERs).

Patients who at $\mathrm{T} 2$ did not achieve an $\mathrm{Hb}$ concentration at least $50 \%$ higher than the original one were classified as not early responders (NERs).

\section{Results and Discussion}

3.1. Patients. Thirty-four pediatric patients, 22 males and 12 females, with a mean (SD) age at diagnosis of 52 (61) months, matched inclusion criteria and were enrolled in the study. Patients' characteristics at diagnosis are set out in Table 1.

3.2. Hemoglobin and Reticulocyte Parameters at T0, T1, and T2. Data regarding values of $\mathrm{Hb}, \mathrm{ARC}$, and $\mathrm{CHr}$ at T0, T1, and $\mathrm{T} 2$ are set out in Table 2.

Mean (SD) Hb level before treatment (T0) was 6.84 (1.22) g/dL. It increased to $7.36 \mathrm{~g} / \mathrm{L}$ (1.31) and $10.56 \mathrm{~g} / \mathrm{L}(1.62)$ at $\mathrm{T} 1$ and $\mathrm{T} 2$, respectively.

Mean (SD) ARC before treatment (T0) was $72799 / \mathrm{mmc}$ (35155). It increased to $168583 / \mathrm{mmc}(101196)$ at $\mathrm{T} 1$ and then decreased again to $76317 / \mathrm{mmc}(38924)$ at T2, respectively.

$\mathrm{CHr}$ could be fully monitored only for 28 patients. Mean $\mathrm{CHr}$ before treatment was $18.20 \mathrm{pg}$ (2.32). It increased to $21.48 \mathrm{pg}$ (3.04) and 25.43 pg (4.49) at T1 and T2, respectively.

Twenty-four/34 patients $(70.5 \%)$ were classified as complete early responders (CERs), 4/34 (12\%) as partial early responders (PERs), and the remaining 6 (17.5\%) as not early responders (NERs).

Data about mean $\mathrm{Hb}, \mathrm{ARC}$, and $\mathrm{CHr}$ at T0, T1, and $\mathrm{T} 2$ in different groups of patients are set out in Tables 3(a) and 3(b).

Trends of mean values of $\mathrm{Hb}, \mathrm{ARC}$, and $\mathrm{CHr}$ in the different groups of children are graphically represented in Figure 1.

3.3. Factors Predictive of Response at Day +30: Comparison between Complete Early Responders and Other Patients. No differences were detected regarding gender and hemoglobin values at diagnosis (T0).

$\mathrm{CHr}$ at T0 was significantly higher in CERs than in remaining patients (19.94 pg versus $16.73 \mathrm{pg} ; p=0.020$ ).

Analysis of $\mathrm{Hb}$ values at $\mathrm{T} 1$ revealed no difference between the two different groups $(7.67 \mathrm{~g} / \mathrm{dL}$ versus $6.63 \mathrm{~g} / \mathrm{dL}$, $p=0.05$ ).

$\mathrm{CHr}$ at $\mathrm{T} 1$ was significantly different between CERs and other patients (22.95 versus $18.41 ; p=0.001)$.

Relative increase of $\mathrm{CHr}$ from $\mathrm{T} 0$ to $\mathrm{T} 1$, computed as (T1 CHr - T0 CHr)/T0 CHr, resulted significantly higher in CERs than in other patients $(0.21$ versus $0.11, p=0.042)$.

Results from multivariate logistic models revealed a higher probability of being a complete early responder due 
TABle 1: Patients' characteristics at diagnosis.

\begin{tabular}{|c|c|c|c|c|c|}
\hline $\begin{array}{l}\text { Patient } \\
\text { (id) }\end{array}$ & $\begin{array}{c}\text { Sex } \\
(\mathrm{M} / \mathrm{F})\end{array}$ & $\begin{array}{c}\text { Age at diagnosis } \\
\text { (months) }\end{array}$ & $\begin{array}{l}\mathrm{Hb} \text { T0 } \\
(\mathrm{g} / \mathrm{dL}) \\
\end{array}$ & $\begin{array}{l}\text { ARC T0 } \\
(n / \mathrm{mmc})\end{array}$ & $\begin{array}{l}\mathrm{CHr} \text { T0 } \\
(\mathrm{pg}) \\
\end{array}$ \\
\hline 1 & M & 9 & 5.8 & 82800 & 15.3 \\
\hline 2 & M & 9 & 5.5 & 79800 & 15.4 \\
\hline 3 & M & 12 & 5.1 & 54100 & 15.4 \\
\hline 4 & M & 48 & 5.0 & 82200 & 15.7 \\
\hline 5 & M & 7 & 5.7 & 148100 & 15.7 \\
\hline 6 & M & 24 & 4.5 & 145700 & 15.8 \\
\hline 7 & $\mathrm{~F}$ & 24 & 6.8 & 89200 & 16.1 \\
\hline 8 & $\mathrm{~F}$ & 24 & 6.1 & 66700 & 16.4 \\
\hline 9 & $\mathrm{~F}$ & 144 & 7.0 & 126000 & 16.7 \\
\hline 10 & $\mathrm{~F}$ & 96 & 6.3 & 92300 & 16.9 \\
\hline 11 & $\mathrm{~F}$ & 72 & 6.3 & 85400 & 17.2 \\
\hline 12 & M & 36 & 7.9 & 78300 & 17.5 \\
\hline 13 & M & 48 & 8.1 & 94000 & 18.0 \\
\hline 14 & M & 7 & 8.7 & 43700 & 18.2 \\
\hline 15 & M & 9 & 6.0 & 56800 & 18.2 \\
\hline 16 & $\mathrm{~F}$ & 36 & 7.8 & 69500 & 18.5 \\
\hline 17 & $\mathrm{~F}$ & 7 & 5.8 & 78000 & 18.8 \\
\hline 18 & M & 11 & 9.3 & 53600 & 18.8 \\
\hline 19 & $\mathrm{~F}$ & 8 & 8.9 & 15500 & 19.0 \\
\hline 20 & $\mathrm{~F}$ & 180 & 7.4 & 63500 & 19.4 \\
\hline 21 & M & 60 & 7.2 & 47700 & 19.7 \\
\hline 22 & M & 192 & 8.5 & 40500 & 20.4 \\
\hline 23 & M & 24 & 7.4 & 46600 & 20.4 \\
\hline 24 & $\mathrm{~F}$ & 156 & 6.8 & 78600 & 20.5 \\
\hline 25 & $\mathrm{~F}$ & 180 & 6.5 & 56100 & 20.6 \\
\hline 26 & M & 48 & 7.9 & 59700 & 21.2 \\
\hline 27 & M & 36 & 8.0 & 19800 & 21.8 \\
\hline 28 & M & 4 & 8.8 & 57700 & 24.8 \\
\hline 29 & M & 192 & 6.3 & 68000 & na \\
\hline 30 & M & 24 & 6.7 & 18600 & na \\
\hline 31 & M & 6 & 6.3 & 132000 & na \\
\hline 32 & M & 24 & 6.0 & 152000 & na \\
\hline 33 & M & 5 & 6.8 & 50000 & na \\
\hline 34 & $\mathrm{~F}$ & 8 & 5.5 & 42000 & na \\
\hline
\end{tabular}

to relative increase of ARC from T0 to $\mathrm{T} 1$ [OR $(95 \% \mathrm{CI})=$ 44.95 (1.54-1311.98); $p<0.030$ ] and to $\mathrm{CHr}$ at T1 [OR (95\% CI) $=3.18(1.24-8.17) ; p=0.016]$. Both models were adjusted by age at diagnosis, sex, and level of $\mathrm{Hb}$ at $\mathrm{T} 0$.

Differences between CERs and other patients are reported in Table 3(a).

3.4. Factors Predictive of Response at Day +30: Comparison between Early Responders and Not Early Responders. When the distinction between early responders and not responders was taken into account, $\mathrm{CHr}$ at $\mathrm{T} 1$ was significantly different in the two groups (22.42 versus 18.07; $p=0.001$ ).
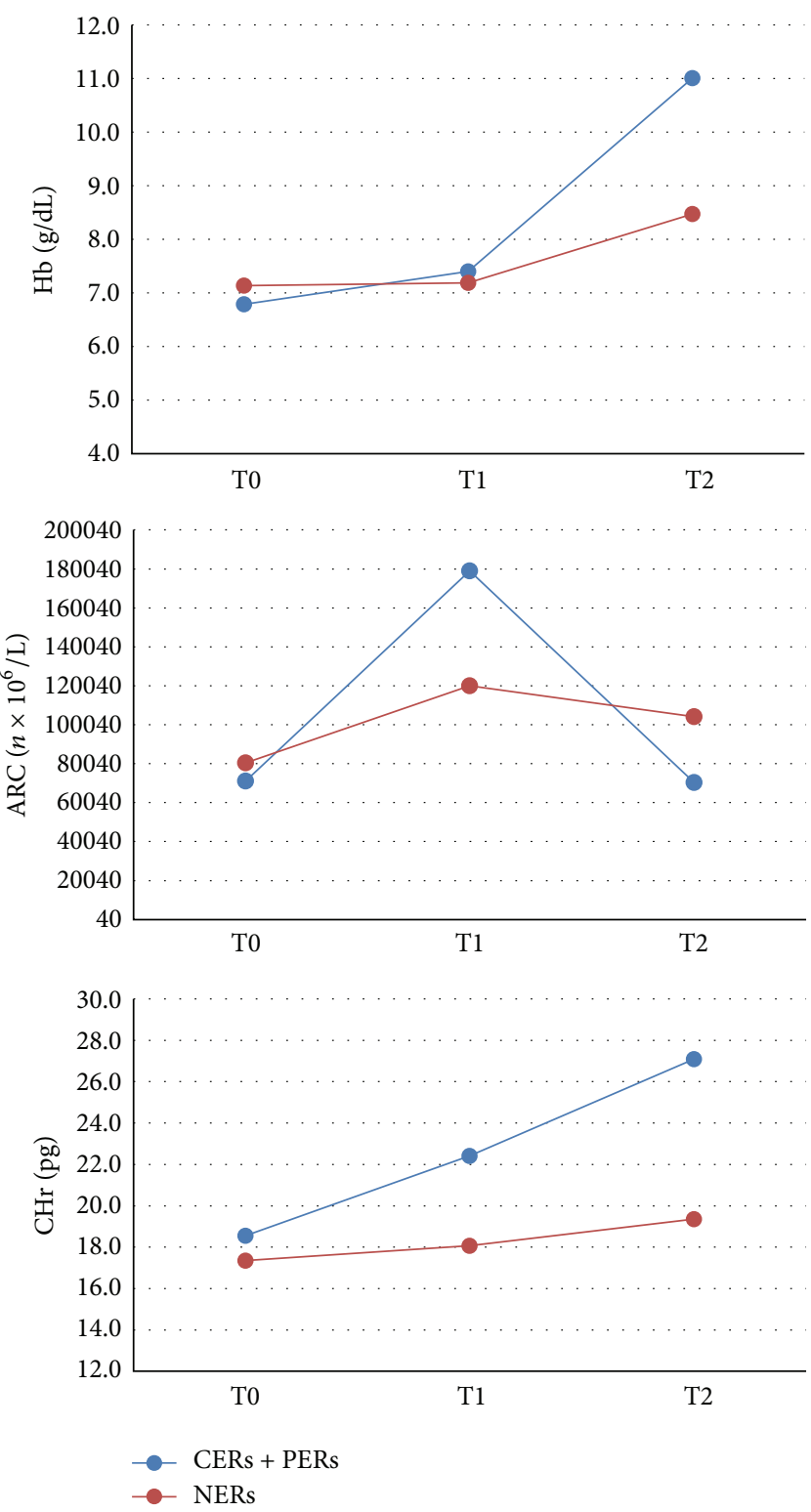

Figure 1: Trends of mean $\mathrm{Hb}, \mathrm{ARC}$, and $\mathrm{CHr}$ values ( $y$-axis) in early responding patients (CERs + PERs) and not early responding patients (NERs) at T0: diagnosis, T1: within 7 days from the beginning of oral iron supplementation, and T2: at +30 from the onset of therapy ( $x$-axis).

Relative increase of $\mathrm{CHr}$ from $\mathrm{T} 0$ to $\mathrm{T} 1$, computed as (T1 $\mathrm{CHr}-\mathrm{T} 0 \mathrm{CHr}$ )/ T0 $\mathrm{CHr}$, resulted significantly higher, too $(0.22$ versus $0.004, p=0.006)$.

Differences between early responders and not responders are reported in Table 3(b).

3.5. Discussion. Our data confirm the efficacy of oral iron administration in promptly improving $\mathrm{Hb}$ values in patients with severe anemia, too.

More than $70 \%$ of patients retrospectively enrolled in the study reached mean hemoglobin $(\mathrm{Hb})$ reference value for age and gender within one month from the initiation 
TABLE 2: Hemoglobin and reticulocyte parameters at T0 (before treatment), T1 (within 7 days from the beginning of oral iron), and at T2 (day +30 from the beginning of treatment).

\begin{tabular}{|c|c|c|c|c|c|c|c|c|c|}
\hline $\begin{array}{l}\text { Patient } \\
\text { (id) }\end{array}$ & $\begin{array}{l}\text { T0 Hb } \\
\text { (g/dL) }\end{array}$ & $\begin{array}{l}\mathrm{T} 1 \mathrm{Hb} \\
(\mathrm{g} / \mathrm{dL}) \\
\end{array}$ & $\begin{array}{l}\mathrm{T} 2 \mathrm{Hb} \\
(\mathrm{g} / \mathrm{dL})\end{array}$ & $\begin{array}{l}\text { T0 ARC } \\
(n / \mathrm{mmc})\end{array}$ & $\begin{array}{c}\text { T1 ARC } \\
(n / \mathrm{mmc})\end{array}$ & $\begin{array}{l}\text { T2 ARC } \\
(n / \mathrm{mmc})\end{array}$ & $\begin{array}{c}\text { T0 CHr } \\
(\mathrm{pg})\end{array}$ & $\begin{array}{c}\mathrm{T} 1 \mathrm{CHr} \\
(\mathrm{pg})\end{array}$ & $\begin{array}{c}\mathrm{T} 2 \mathrm{CHr} \\
(\mathrm{pg})\end{array}$ \\
\hline 1 & 5.8 & 6.3 & 9.1 & 82800 & 182200 & 84200 & 15.3 & 21.0 & 26.0 \\
\hline 2 & 5.5 & 5.7 & 8.4 & 79800 & 137300 & 141300 & 15.4 & 15.8 & 19.6 \\
\hline 3 & 5.1 & 5.9 & 11.1 & 54100 & 99100 & 44000 & 15.4 & 18.7 & 29.8 \\
\hline 4 & 5.0 & 4.9 & 7.0 & 82200 & 126300 & 78900 & 15.7 & 16.8 & 16.4 \\
\hline 5 & 5.7 & 5.9 & 8.0 & 148100 & 232000 & 154100 & 15.7 & 17.5 & 17.7 \\
\hline 6 & 4.5 & 4.5 & 9.4 & 145700 & 209400 & 122200 & 15.8 & 20.5 & 24.9 \\
\hline 7 & 6.8 & 7.6 & 12.9 & 89200 & 190000 & 47400 & 16.1 & 21.9 & 25.2 \\
\hline 8 & 6.1 & 7.2 & 13.2 & 66700 & 155300 & 31500 & 16.4 & 24.2 & 30.1 \\
\hline 9 & 7.0 & 7.2 & 12.4 & 126000 & 201400 & 106200 & 16.7 & 19.9 & 29.0 \\
\hline 10 & 6.3 & 7.1 & 11.8 & 92300 & 315000 & 79400 & 16.9 & 22.3 & 27.2 \\
\hline 11 & 6.3 & 6.1 & 7.4 & 85400 & 134500 & 107000 & 17.2 & 18.3 & 19.3 \\
\hline 12 & 7.9 & 8.1 & 9.8 & 78300 & 110600 & 66000 & 17.5 & 20.8 & 23.7 \\
\hline 13 & 8.1 & 8.6 & 10.5 & 94000 & 148200 & 54300 & 18.0 & 23.8 & 27.6 \\
\hline 14 & 8.7 & 9.7 & 9.4 & 43700 & 71600 & 67100 & 18.2 & 18.8 & 18.1 \\
\hline 15 & 6.0 & 7.0 & 12.2 & 56800 & 108200 & 60000 & 18.2 & 19.7 & 26.6 \\
\hline 16 & 7.8 & 7.4 & 9.5 & 69500 & 71500 & 69500 & 18.5 & 19.3 & 23.6 \\
\hline 17 & 5.8 & 6.3 & 12.4 & 78000 & 232000 & 43800 & 18.8 & 21.0 & 31.3 \\
\hline 18 & 9.3 & 9.1 & 9.5 & 53600 & 84200 & 148300 & 18.8 & 17.7 & 21.0 \\
\hline 19 & 8.9 & 9.3 & 10.5 & 15500 & 262500 & 61900 & 19.0 & 25.6 & 22.5 \\
\hline 20 & 7.4 & 8.8 & 10.8 & 63500 & 148100 & 44800 & 19.4 & 27.3 & 27.6 \\
\hline 21 & 7.2 & 7.2 & 12.5 & 47700 & 155900 & 71100 & 19.7 & 22.7 & 28.9 \\
\hline 22 & 8.5 & 8.4 & 10.5 & 40500 & 44600 & 70100 & 20.4 & 25.7 & 26.2 \\
\hline 23 & 7.4 & 8.8 & 10.5 & 46600 & 240300 & 42200 & 20.4 & 26.7 & 32.1 \\
\hline 24 & 6.8 & 7.7 & 13.7 & 78600 & 105500 & 26100 & 20.5 & 24.3 & 32.0 \\
\hline 25 & 6.5 & 8.9 & 10.7 & 56100 & 149900 & 188500 & 20.6 & 22.6 & 22.3 \\
\hline 26 & 7.9 & 7.5 & 10.4 & 59700 & 93900 & 35400 & 21.2 & 22.0 & 26.3 \\
\hline 27 & 8.0 & 8.9 & 11.8 & 19800 & 42000 & 63500 & 21.8 & 22.9 & 30.9 \\
\hline 28 & 8.8 & 9.2 & 10.8 & 57700 & 59200 & 75500 & 24.8 & 23.9 & 26.2 \\
\hline 29 & 6.3 & 6.9 & 10.0 & 68000 & 101340 & 82800 & na & na & na \\
\hline 30 & 6.7 & 8.0 & 10.0 & 18600 & 345700 & 26400 & na & na & na \\
\hline 31 & 6.3 & 6.7 & 12.4 & 132000 & 294100 & 37000 & na & na & na \\
\hline 32 & 6.0 & 6.7 & 9.3 & 152000 & 233000 & 103000 & na & na & na \\
\hline 33 & 6.8 & 6.7 & 9.8 & 50000 & 110000 & 94500 & na & na & na \\
\hline 34 & 5.5 & 6.0 & 11.2 & 42000 & 537000 & 66800 & na & na & na \\
\hline
\end{tabular}

of treatment, independently from base $\mathrm{Hb}$ level. Only a negligible percentage of children did not reach an $\mathrm{Hb}$ concentration at least $50 \%$ higher than the original after one month of therapy and was therefore classified as unresponsive to therapy. As our patients have not been tested for alpha and beta thalassemia at diagnosis or during the first month of therapy, we cannot rule out the possibility that these children have not responded to iron because of a concomitant hemoglobinopathy.

Measurement of reticulocyte hemoglobin content $(\mathrm{CHr})$ has been validated in literature as the strongest independent predictor of iron deficiency and iron deficiency anemia, when compared to other laboratory markers (hemoglobin, ferritin, transferrin saturation, or mean corpuscular volume), both in children and in adults [1]. In pediatric patients, optimal $\mathrm{CHr}$ cut-off has been proven to be $27.5 \mathrm{pg}$ for detecting iron deficiency (with a sensitivity of $83 \%$ and a specificity of $72 \%$ ) [3] and $26 \mathrm{pg}$ for detecting iron deficiency anemia (with a sensitivity of $83 \%$ and a specificity of $75 \%$ ) [2]. In the totality of children described in our cohort (all displaying severe iron deficiency, defined by a transferrin saturation value of less than 10\%), CHr levels were significantly lower than cut-off level of $26 \mathrm{pg}$ ( $p<0.001$ for corresponding Wilcoxon test), and in $75 \%$ of children resulted even less than $20 \mathrm{pg}$. 
TABLE 3: Descriptive characteristics of patients, divided into CERs $=$ complete early responders (i.e., normal Hb value at day +30 for therapy onset), PERs $=$ partial early responders ( $\mathrm{Hb}$ value at day +30 at least $50 \%$ higher than the original one), and NERs $=$ not early responders. $p$ values come from Wilcoxon sum rank test.

(a)

\begin{tabular}{|c|c|c|c|c|c|}
\hline & \multicolumn{2}{|c|}{ CERs $(n=24)$} & \multicolumn{2}{|c|}{ PERs + NERs $(n=10)$} & \multirow[b]{2}{*}{$p$ value } \\
\hline & $n$ & $(\%)$ & $n$ & $(\%)$ & \\
\hline Male & 14 & $(63.64 \%)$ & 8 & $(36.36 \%)$ & \multirow{2}{*}{0.430} \\
\hline \multirow[t]{2}{*}{ Female } & 10 & $(83.33 \%)$ & 2 & $(16.67 \%)$ & \\
\hline & Mean & (SD) & Mean & $(\mathrm{SD})$ & $p$ value \\
\hline T0 Hb (g/dL) & 7.00 & $(1.03)$ & 6.46 & $(1.60)$ & 0.134 \\
\hline $\mathrm{T} 1 \mathrm{Hb}(\mathrm{g} / \mathrm{dL})$ & 7.67 & $(1.02)$ & 6.63 & $(1.68)$ & 0.050 \\
\hline $\mathrm{T} 2 \mathrm{Hb}(\mathrm{g} / \mathrm{dL})$ & 11.33 & $(1.15)$ & 8.70 & $(0.94)$ & $<0.001$ \\
\hline T0 $\operatorname{ARC}(n / \mathrm{mmc})$ & 63820 & (29399) & 94280 & $(39813)$ & 0.040 \\
\hline $\mathrm{T} 1 \mathrm{ARC}(n / \mathrm{mmc})$ & 177077 & $(113504)$ & 148200 & $(63023)$ & 0.620 \\
\hline $\mathrm{T} 2 \operatorname{ARC}(n / \mathrm{mmc})$ & 63300 & $(33954)$ & 107560 & $(32749)$ & 0.002 \\
\hline (T1 ARC - T0 ARC)/T0 ARC & 2.92 & $(4.87)$ & 0.58 & $(0.29)$ & 0.023 \\
\hline T0 CHr (pg) & $19.04^{*}$ & $(2.33)$ & $16.73^{\circ}$ & $(1.44)$ & 0.020 \\
\hline $\mathrm{T} 1 \mathrm{CHr}$ (pg) & $22.95^{*}$ & $(2.38)$ & $18.41^{\circ}$ & $(1.69)$ & 0.001 \\
\hline T2 CHr (pg) & $27.66^{*}$ & $(2.99)$ & $20.73^{\circ}$ & $(3.38)$ & 0.001 \\
\hline \multirow[t]{2}{*}{ (T1 CHr-T0 CHr)/T0 CHr } & $0.21^{*}$ & $(0.14)$ & $0.11^{\circ}$ & $(0.14)$ & 0.042 \\
\hline & ${ }^{*} n=19$ & & ${ }^{\circ} n=9$ & & \\
\hline
\end{tabular}

(b)

\begin{tabular}{|c|c|c|c|c|c|}
\hline & \multicolumn{2}{|c|}{ CERs + PERs $(n=28)$} & \multicolumn{2}{|c|}{ NERs $(n=6)$} & \multirow[b]{2}{*}{$p$ value } \\
\hline & $n$ & (\%) & $n$ & $(\%)$ & \\
\hline Male & 18 & $(81.82 \%)$ & 4 & $(18.18 \%)$ & \multirow{2}{*}{1.000} \\
\hline \multirow[t]{2}{*}{ Female } & 10 & $(83.33 \%)$ & 2 & $(16.67 \%)$ & \\
\hline & Mean & (SD) & Mean & $(\mathrm{SD})$ & $p$ value \\
\hline T0 Hb (g/dL) & 6.78 & $(1.12)$ & 7.13 & $(1.73)$ & 0.790 \\
\hline T0 Hb (g/dL) & 7.40 & $(1.20)$ & 7.18 & $(1.90)$ & 0.750 \\
\hline T0 $\mathrm{Hb}(\mathrm{g} / \mathrm{dL})$ & 11.00 & $(1.35)$ & 8.47 & $(1.14)$ & 0.001 \\
\hline T0 ARC $(n / \mathrm{mmc})$ & 71143 & $(35210)$ & 80417 & $(36866)$ & 0.580 \\
\hline T0 $\operatorname{ARC}(n / \mathrm{mmc})$ & 178991 & (105758) & 120017 & $(61270)$ & 0.120 \\
\hline T0 $\operatorname{ARC}(n / \mathrm{mmc})$ & 70354 & $(36863)$ & 104150 & (39149) & 0.040 \\
\hline (T1 ARC-T0 ARC)/T0 ARC & 2.60 & $(4.56)$ & 0.49 & $(0.23)$ & 0.005 \\
\hline T0 CHr (pg) & $18.56^{*}$ & $(2.49)$ & $17.35^{\circ}$ & $(1.39)$ & 0.300 \\
\hline T1 CHr (pg) & $22.42^{*}$ & $(2.73)$ & $18.07^{\circ}$ & $(0.91)$ & 0.001 \\
\hline T2 CHr (pg) & $27.09^{*}$ & $(3.30)$ & $19.35^{\circ}$ & $(2.60)$ & $<0.001$ \\
\hline \multirow[t]{2}{*}{ (T1 CHr-T0 CHr)/T0 CHr } & $0.22^{*}$ & $(0.14)$ & $0.04^{\circ}$ & $(0.06)$ & 0.006 \\
\hline & ${ }^{*} n=22$ & & ${ }^{\circ} n=6$ & & \\
\hline
\end{tabular}

The finding that $\mathrm{CHr}$ at T0 was significantly lower in patients who did not reach normal $\mathrm{Hb}$ levels at day +30 raises the intriguing possibility that $\mathrm{CHr}$ level at diagnosis might be a predictor of early response to oral iron. To our knowledge, no data about this issue are present in literature to date. Due to the limitations derived from the small sample size, our results need to be confirmed on larger cohorts of patients.

As reticulocyte indices allow a real-time evaluation of iron deficient erythropoiesis and of the effectiveness of iron replacement therapy [1], $\mathrm{CHr}$ has been validated in literature as an early predictor of response to parenteral iron therapy, in children receiving hemodialysis [10] and in adults [6].

Similar conclusion regarding response to exclusive oral iron therapy in a small cohort of children with severe iron deficiency anemia had been previously reported by our group [9]. Main outcome of our preliminary study [9] was to evaluate if oral iron supplementation should be proposed as first-line treatment in a small cohort of clinically asymptomatic patients with severe iron deficiency anemia. These patients, due to their $\mathrm{Hb}$ levels (median $6.3 \mathrm{~g} / \mathrm{dL}$, range 
4.5-7), needed a tight follow-up; for that reason, the kinetic of response was assessed within 48 hours from the onset of iron administration (T1) and our data demonstrated the utility of ARC and $\mathrm{CHr}$ as accurate markers for the early detection of patients not responding to oral iron to be quickly switched to other therapies (parenteral iron supplementation or transfusion). These results prompted us to investigate the efficacy of reticulocyte parameters in monitoring the response to oral iron supplementation in a larger cohort of pediatric patients.

Despite the limitations derived from the retrospective nature of the study, analysis of reticulocyte parameters within one week from the beginning of therapy confirmed $\mathrm{CHr}$ to predict good early hematologic response to iron supplements after one week of therapy.

In particular, both $\mathrm{CHr}$ levels within 7 days from the beginning of therapy and the relative increase of $\mathrm{CHr}$ from $\mathrm{T} 0$ to $\mathrm{T} 1$ resulted significantly higher in patients who displayed normal hemoglobin levels or a hemoglobin concentration at least $50 \%$ higher than the original one at day +30 .

\section{Conclusions}

Aim of the present study was to evaluate kinetic of response to oral iron in a cohort of pediatric patients with iron deficiency anemia and to investigate the usefulness of reticulocyte parameters $\mathrm{CHr}$ and $\mathrm{ARC}$ in monitoring early response to iron supplementation.

Despite the limitations derived from both the small number of patients and the retrospective nature of the study, according to data of literature, our data confirm that oral iron supplementation is an effective treatment for iron deficiency anemia, independently from base hemoglobin at diagnosis.

Moreover, our preliminary data suggest that reticulocyte parameters are early and accurate predictors of response to oral therapy and that pediatricians could take advantage of reticulocyte hemoglobin content both at diagnosis and during follow-up of iron deficiency anemia for assessing early erythropoietic response to iron replacement therapy.

A prospective multicentre study on a larger cohort of patients is ongoing in order to reinforce our conclusions.

\section{Competing Interests}

The authors have no competing interests to declare.

\section{References}

[1] E. Piva, C. Brugnara, F. Spolaore, and M. Plebani, "Clinical utility of reticulocyte parameters," Clinics in Laboratory Medicine, vol. 35, no. 1, pp. 133-163, 2015.

[2] C. Brugnara, D. Zurakowski, J. DiCanzio, T. Boyd, and O. Platt, "Reticulocyte hemoglobin content to diagnose iron deficiency in children," The Journal of the American Medical Association, vol. 281, no. 23, pp. 2225-2230, 1999.

[3] C. Ullrich, A. Wu, C. Armsby et al., "Screening healthy infants for iron deficiency using reticulocyte hemoglobin content," The Journal of the American Medical Association, vol. 294, no. 8, pp. 924-930, 2005.
[4] A. F. Bakr and G. Sarette, "Measurement of reticulocyte hemoglobin content to diagnose iron deficiency in Saudi children," European Journal of Pediatrics, vol. 165, no. 7, pp. 442-445, 2006.

[5] A. E. Mast, M. A. Blinder, and D. J. Dietzen, "Reticulocyte hemoglobin content," American Journal of Hematology, vol. 83, no. 4, pp. 307-310, 2008.

[6] C. Brugnara, M. R. Laufer, A. J. Friedman, K. Bridges, and O. Platt, "Reticulocyte hemoglobin content $(\mathrm{CHr})$ : early indicator of iron deficiency and response to therapy," Blood, vol. 83, no. 10, pp. 3100-3101, 1994.

[7] C. Borgna-Pignatti and M. Marsella, "Iron deficiency in infancy and childhood," Pediatric Annals, vol. 37, no. 5, pp. 329-337, 2008.

[8] X. Zeng and T. Wu, "Iron supplementation for iron deficiency anemia in children," Cochrane Database of Systematic Reviews, no. 2, Article ID CD006465, 2007.

[9] E. Parodi, M. T. Giraudo, M. Davitto et al., "Reticulocyte parameters: markers of early response to oral treatment in children with severe iron-deficiency anemia," Journal of Pediatric Hematology/Oncology, vol. 34, no. 6, pp. e249-e252, 2012.

[10] B. A. Warady, A. Kausz, G. Lerner et al., "Iron therapy in the pediatric hemodialysis population," Pediatric Nephrology, vol. 19, no. 6, pp. 655-661, 2004. 


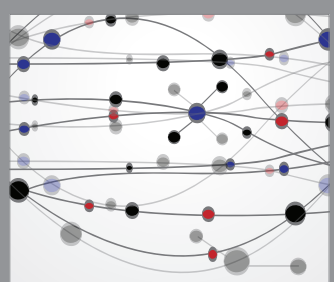

The Scientific World Journal
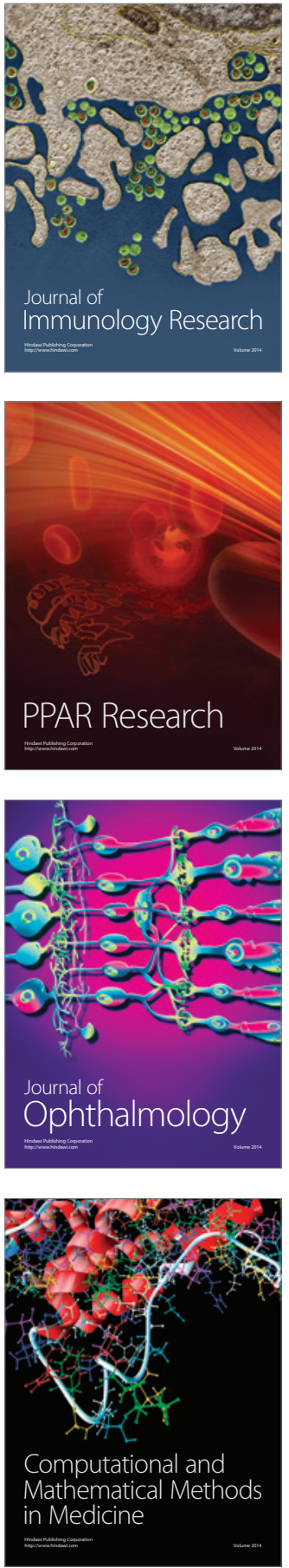

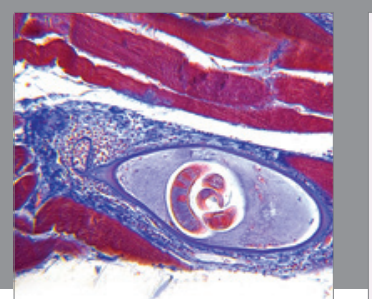

Gastroenterology Research and Practice

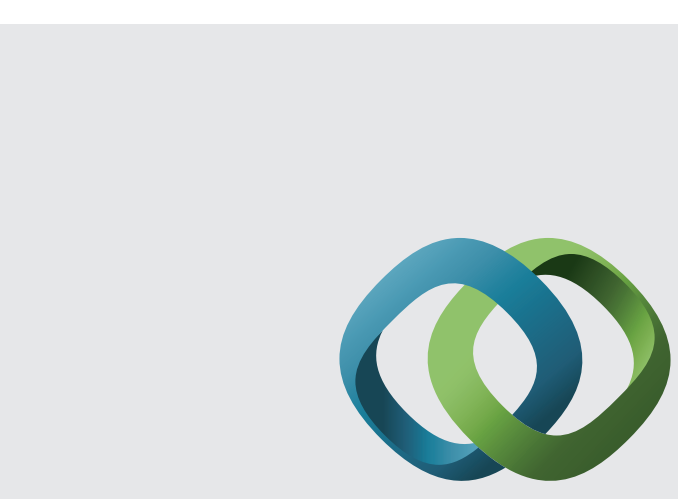

\section{Hindawi}

Submit your manuscripts at

http://www.hindawi.com
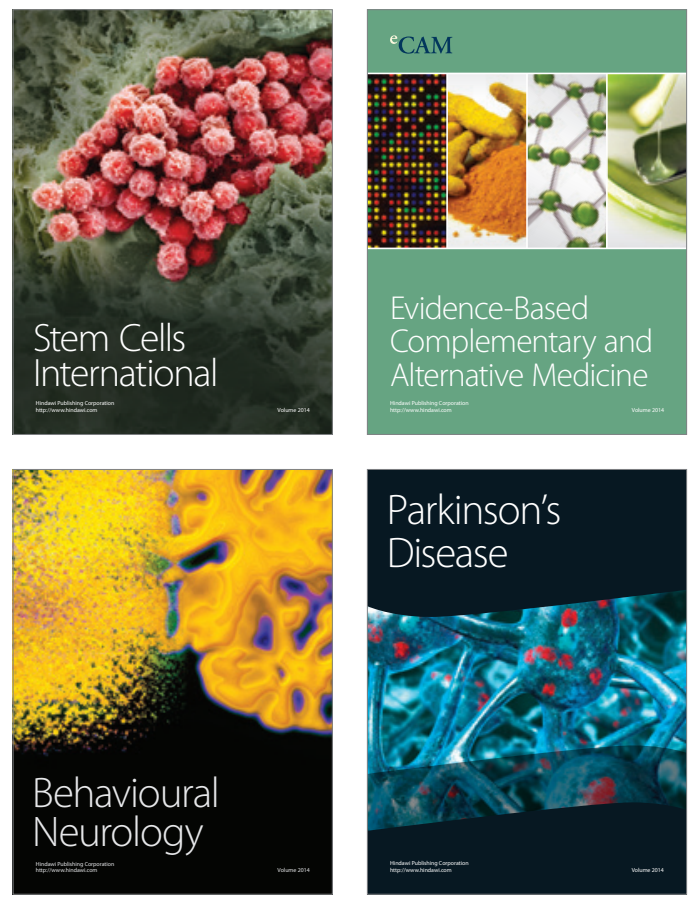
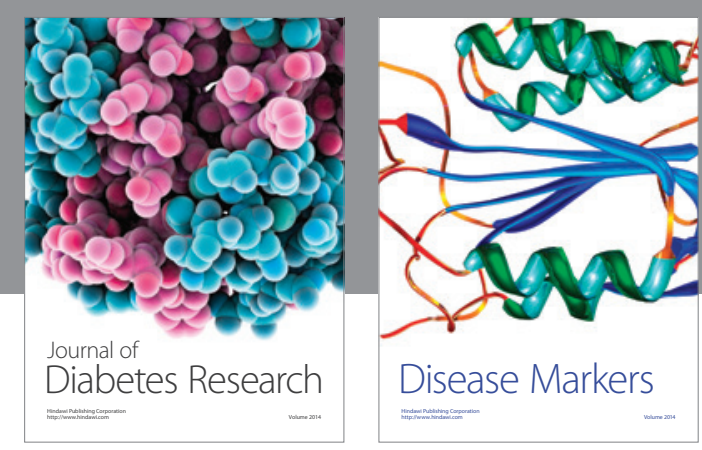

Disease Markers
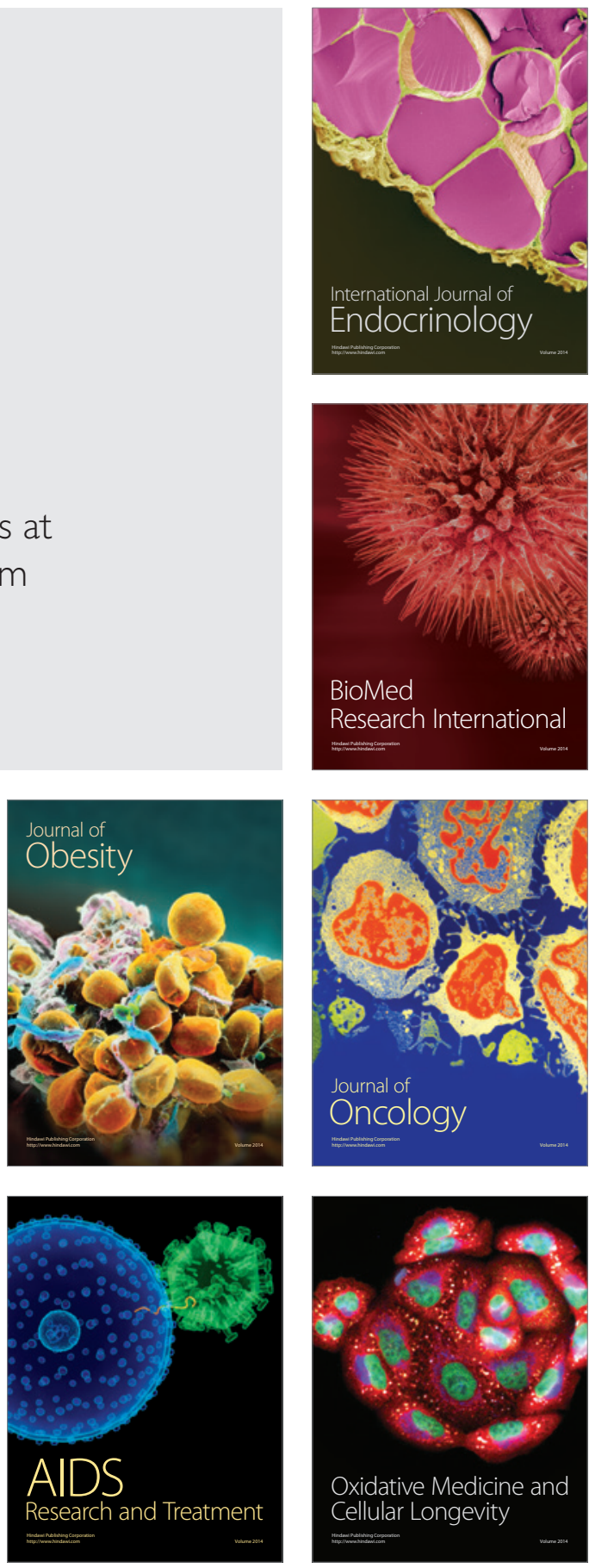